\title{
cDNA Array Analysis of Gene Expression Profiles in Brain of Mice Exposed to Manganese
}

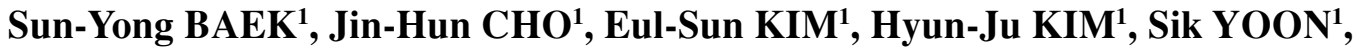 \\ Bong-Seon KIM ${ }^{1}$, Jae-Bong KIM${ }^{1}$, Choong-Ryeol LEE $^{2}$, Cheolin YOO², \\ Ji-Ho LEE ${ }^{2}$, Hun LEE ${ }^{2}$, Jungsun PARK ${ }^{3}$, Jae-Woo KIM ${ }^{4}$ and Yangho KIM*
}

\author{
${ }^{1}$ Department of Anatomy, College of Medicine, Pusan National University, Busan, South Korea \\ ${ }^{2}$ Department of Occupational and Environmental Medicine, Ulsan University Hospital, \#290-3 Cheonha-Dong, \\ Dong-Ku, Ulsan, 682-060, South Korea \\ ${ }^{3}$ Korea Occupational Safety and Health Agency, Inchon, South Korea \\ ${ }^{4}$ Department of Neurology, Dong-A University School of Medicine, Busan, South Korea
}

Received October 21, 2003 and accepted March 17, 2004

\begin{abstract}
This study is performed to detect changes of gene expression in substantia nigra (SN) and striatum in manganese (Mn)-exposed mice brain. The cDNA array is a recently developed molecular biological method that can detect the differential expression of several hundreds of genes simultaneously and is therefore advantageous in the study of trace metal intoxication effect at the genetic level. Using this technology, we discovered 5 genes in the mouse striatum and 9 genes in SN changed by more than 50\% following Mn exposure. Depression were observed in two genes (neural cell adhesion protein BIG2, heavy neurofilament subunit genes) in striatum and three genes (light neurofilament subunit, brain acyl-CoA synthetase II, heavy neurofilament subunit genes) in the SN. However three genes ( $\mathrm{N}$-acetylglucosaminyltransferase $\mathrm{I}, \mathrm{S100} \beta$, and synaptonemal complex protein I genes) in striatum and six genes (noggin, striatin, Ost oncogene, $\mathrm{S100} \beta$, calcium/calmodulindependent protein kinase kinase beta, and $\mathbf{N}$-acetylglucosaminyltransferase $\mathrm{I}$ genes) in $\mathrm{SN}$ were elevated following Mn exposure. Immunohistochemical study revealed that protein levels of S100 $\beta$ also increased following Mn treatment. Activated astrocytes overexpressing S100 $\beta$ are invariably and intimately associated with decreased expression of heavy and light neurofilament subunits which is a distinguishing feature of neurodegeneration by Mn exposure. All our findings suggested that neuronal degenerations occur in $\mathrm{SN}$ as well as striatum of mice exposed to $\mathrm{Mn}$.
\end{abstract}

Key words: cDNA array, Gene expression, Mouse, Brain, Manganese

\section{Introduction}

Manganese (Mn) is an essential element for metalloproteins, such as glutamate synthetase, mitochondrial superoxide dismutase ${ }^{1,2)}$. However excessive $\mathrm{Mn}$ is also toxic to brain and can produce an irreversible syndrome resembling Parkinson's disease ${ }^{3,4)}$. Oxidative stress has been suggested as the underlying mechanism of Mn neurotoxicity. Mn may stimulate dopamine autoxidation within the

*To whom correspondence should be addressed. dopaminergic neuron, a process accompanied by an increase in formation of reactive oxygen species and quinones. The pursuant oxidative stress has been proposed as being responsible for the neuronal damage. But there is few reports about changes in gene levels by $\mathrm{Mn}$ intoxication in mammals.

There are several techniques that can be used to examine gene transcription, such as reverse-transcriptase coupled to the polymerase chain reaction (RT-PCR), differential display, and serial analysis of gene expression (SAGE), however, these procedures are labor intensive and are limited in the number of genes that can be monitored simultaneously. In 
contrast, monitoring the expression level of thousands of genes is feasible when using cDNA array-based techniques ${ }^{5)}$. The use of cDNA arrays to identify gene modulation events associated with toxicity may enable to detect toxicant exposure at an earlier time than the methods to identify protein products or terminal cellular processes. In addition, the highly sensitive cDNA arrays can detect gene expression events associated with low-level toxicity ${ }^{6}$. Although microarrays have been used to examine differential gene expression in static systems, such as cultures of healthy and diseased cells, the ability of this tool to identify gene modulation events reproducibly is unclear.

In the present study, a mouse model was used to examine the effects of Mn exposure on gene expression in the striatum and substantia nigra (SN) of mice brain.

\section{Materials and Methods}

\section{Animals}

These experiments were carried out using a previously reported regimen of $\mathrm{Mn}$ exposure ${ }^{7)}$. Male C57BL/6 mice (10 wk old, body weight $25-30 \mathrm{~g}$ ) were caged in an airconditioned room maintained at $22 \pm 2{ }^{\circ} \mathrm{C}$, relative humidity $50 \pm 10 \%$, with a $12 / 12 \mathrm{~h}$ light/dark cycle. The animals had free access to tap water and were fed a conventional rat chow diet ad libitum. The animals acclimated for $2 \mathrm{wk}$ prior to the beginning of the study. All procedures related to animal care were in accordance with the guidelines for the Care and Use of Laboratory Animals of College of Medicine, Pusan National University. The mice were allocated randomly into two groups: Mn exposure group $(n=7)$ and control group $(n=7)$. Three out of seven were used for cDNA array, and the others for immunohistochemical analysis. Following acclimation, the exposure group received intraperitoneally with $0.2 \mathrm{ml}$ of $\mathrm{MnCl}_{2} \cdot 4 \mathrm{H}_{2} \mathrm{O}$ (Sigma) $(2 \mathrm{mg}$ $\mathrm{Mn} / \mathrm{kg}$ body weight) once a day for $3 \mathrm{wk}$. The control group received the same volume of saline intraperitoneally.

\section{Animal dissection and tissue handling/storage}

Animals were anesthetized with ether and killed by decapitation at the next day of last Mn injection. Brains were quickly removed and sliced in a contour-fit brain matrix and dissected for striatum including caudate-putamen and globus pallidus, and ventral midbrain region including SN.

\section{RNA isolation}

Total RNA was isolated from dissected brain tissue using Trizol reagent, following the procedure described by the reagent's manufacture (Invitrogen-Life Technologies).
Isolated RNA sample were dissolved in RNase-free water and treated with DNase to remove any genomic DNA contamination. The optical densities of the samples were measured at $260 \mathrm{~nm}$ (A260) and $280 \mathrm{~nm}$ (A280) wavelengths and ratios were calculated. Only samples with A260/A280 ratios $>1.7$ were used for further study. The integrity of each sample was examined by running a small fraction ( 2 $\mathrm{ug}$ ) of the total amount on a $1 \%$ agarose gel $(100 \mathrm{~V}, 1 \mathrm{~h})$ and staining the gel with ethidium bromide to dertermine the relative intensities of the $28 \mathrm{~S}$ and $18 \mathrm{~S}$ rRNA bands.

cDNA array probe preparation and hybridization, and array analysis

An Atlas Mouse 1.2 Array Kit (lot No.:110360) (Clontech, Palo Alto, CA, USA) was used according to the protocol outlined by the manufacturer. The experiment was performed on the Mn-treated RNA samples $(n=4)$ concurrently with their corresponding control RNA samples $(n=4)$ in duplicate. One array was used for each mouse RNA sample (i.e. samples within each expermental group were not mixed) for a total four duplicate array hybridizations per experimental group. ${ }^{32} \mathrm{P}$-labeled cDNA probes were generated from each RNA sample through reverse transcription using Moloney Murine Leukemia Virus (MMLV) reverse transcriptase and primers specific for the gene sequences contained in the kit's cDNA array. Each array consists of 1,176 known mouse genes. Only probes with specific activity of between 2 and $10 \times$ $10^{6} \mathrm{cpm} / \mathrm{sample}$ were used in subsequent hybridization steps. Pre-hybridization was performed on the kit's cDNA arrays using the ExpressHyb solution provided. Probes were then hybridized to the cDNA arrays in roller bottles overnight at $68^{\circ} \mathrm{C}$ in a hybridization chamber. Following stringent washes, the arrays were exposed to phosphor storage screens overnight and then viewed on a phosphorimager. The resulting images were analyzed for differential gene expression using AtlasImage 2.0 software (Clontech).

\section{Immunohistochemistry and image analysis}

Mn-treated animals $(n=3)$ and control animals $(n=3)$ were anesthetized with pentobarbital sodium $(50 \mathrm{mg} / \mathrm{kg})$ at the next day of last Mn injection. Animals were killed by intracardiac perfusion with $4 \%$ paraformaldehyde in a 0.1 $\mathrm{M}$ phosphate buffer, $\mathrm{pH} 7.4$ (PB). Brains were postfixed for $5 \mathrm{~h}$ at $4^{\circ} \mathrm{C}$ and cryoprotected with $30 \%$ sucrose. Tissue was frozen with an OCT compound-embedding medium in dry ice powder. Thirty micrometer coronal sections were cut using cryostat and processed for immunohistochemistry.

Immunohistochemical reaction was performed every 6 th section of the striatum and midbrain. Sections were incubated 
Table 1. Genes showing $>\mathbf{5 0 \%}$ change in expression by $\mathrm{Mn}$ treatment in striatum

\begin{tabular}{lcc}
\hline Gene & $\begin{array}{c}\text { GenBank } \\
\text { Accession No. }\end{array}$ & $\begin{array}{c}\text { Relative expression } \\
\text { change (Mn/control) }\end{array}$ \\
\hline Neural cell adhesion protein BIG2 & U35371 & $0.14 \pm 0.08$ \\
Heavy neurofilament subunit (NF-H) & M21964 & $0.40 \pm 0.05$ \\
N-acetylglucosaminyltransferase I & D16302 & $1.70 \pm 0.12$ \\
S100 calcium-binding protein, beta & M54919 & $4.93 \pm 0.50$ \\
Synaptonemal complex protein 1 & X67805 & $6.00 \pm 0.37$ \\
\hline
\end{tabular}

Table 2. Genes showing $>\mathbf{5 0} \%$ change in expression by Mn treatment in substantia nigra

\begin{tabular}{lcc}
\hline Gene & $\begin{array}{c}\text { GenBank } \\
\text { Accession No. }\end{array}$ & $\begin{array}{c}\text { Relative expression } \\
\text { change (Mn/control) }\end{array}$ \\
\hline Light neurofilament subunit (NF-L) & AF031880 & $0.02 \pm 0.01$ \\
Brain acyl-CoA synthetase II & D30666 & $0.20 \pm 0.08$ \\
Heavy neurofilament subunit (NF-H) & M21964 & $0.48 \pm 0.12$ \\
Noggin & U31203 & $1.60 \pm 0.09$ \\
Striatin & X99326 & $1.81 \pm 0.02$ \\
Ost oncogene & Z35654 & $2.12 \pm 0.12$ \\
S100 calcium-binding protein, beta & M54919 & $3.26 \pm 0.47$ \\
Calcium/calmodulin-dependent protein kinase kinase beta & AB018081 & $6.90 \pm 0.22$ \\
$\quad$ CAM kinase kinase beta; CAMKKB) & & \\
N-acetylglucosaminyltransferase I & D16302 & $7.52 \pm 0.57$ \\
\hline
\end{tabular}

in a blocking buffer $(0.3 \%$ Triton X-100 and $10 \%$ goat serum in PBS) for $1 \mathrm{~h}$, followed by overnight incubation with primary antibodies to $\mathrm{S} 100 \beta$ (rabbit polyclonal anti- $\mathrm{S} 100 \beta$ 1:5000; Swant, Switzland) diluted in an incubation buffer $(0.1 \%$ Triton $\mathrm{X}-100,1 \%$ goat serum and $1 \%$ bovine serum albumin in PBS) at $4^{\circ} \mathrm{C}$. Sections were then washed 3 times for $10 \mathrm{~min}$ each with PBS and incubated in biotinylated goat antirabbit IgG (1:200, Vector laboratories, Burlingame, CA, USA) for $2 \mathrm{~h}$ at room temperature. Sections were washed and processed with $0.05 \%$ 3,3'-diaminobenzidine tetrahydrochloride (SigmaAldrich) with $0.01 \% \mathrm{H}_{2} \mathrm{O}_{2}$. For all incubation and rinse steps, the sections were agitated on a shaker table. After processing, the sections were washed, mounted on coated slides, dried, dehydrated through graded alcohols, cleared in xylene, and coverslipped with an Entellan mountant medium (Merck).

Forebrain sections containing the rostral, middle and caudal levels of striatum, were chosen for image analysis. We measured the optical density of $\mathrm{S} 100 \beta$-immunoreacivity in the striatum of Mn-treated and saline-treated control animals using the Metamorpho 4.7 Image program (Universal Image Corporation, USA) on PC computer connected to a digital camera with constant illumination. To estimate the specific staining density, the optical density reading was corrected for non-specific background density, as measured from regions with no $\mathrm{S} 100 \beta$ immunoreactivity. Data were presented as a percentage area of the total measured area (\% area).

\section{Statistical analyses}

The statistical significance of the difference in the means of variables between the Mn-exposed and the controls group was determined using Student's t tests.

\section{Results}

No significant changes were observed in body weights and diet amounts between Mn-exposed and control group during the experiments.

We considered the positive signals as genes showing an expression change of more than $50 \%$ between control and Mn-treated groups in each striatal and SN. Based on these criteria, 5 array genes in striatum and 9 array genes in SN were differentially expressed at RNA transcript level. Of these genes, two were down-regulated, and three were upregulated in the striatum (Table 1), while three were downregulated, and six were up-regulated in the SN (Table 2). No significant differences in expression of the considered genes were found between mice of the same experimental group. Figure 1 represents the images of the hybridized 


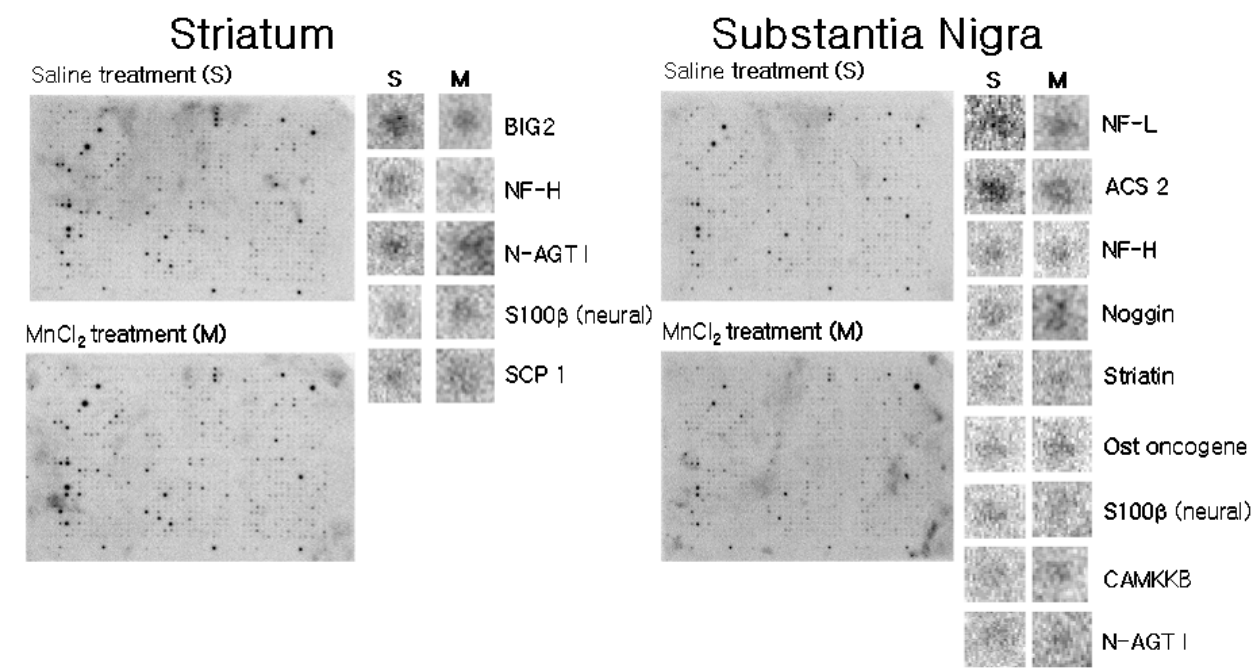

Fig. 1. Representative cDNA arrays showing striatal and substantia nigral gene expression profiles of the saline-treated control $(n=4)$ and Mn-treated mice $(n=4)$. Selected spots have been enlarged to illustrate the observed differences in array analysis more clearly.

BIG2: neural cell adhesion protein BIG2, NF-H: heavy neurofilament subunit, N-AGT I: Nacetylglucosaminyltransferase I, SCP 1: synaptonemal complex protein 1, NF-L: light neurofilament subunit, ACS II: brain acyl-CoA synthetase II, CAMKKB: calcium/calmodulin-dependent protein kinase kinase beta, N-AGT I: N-acetylglucosaminyltransferase I.
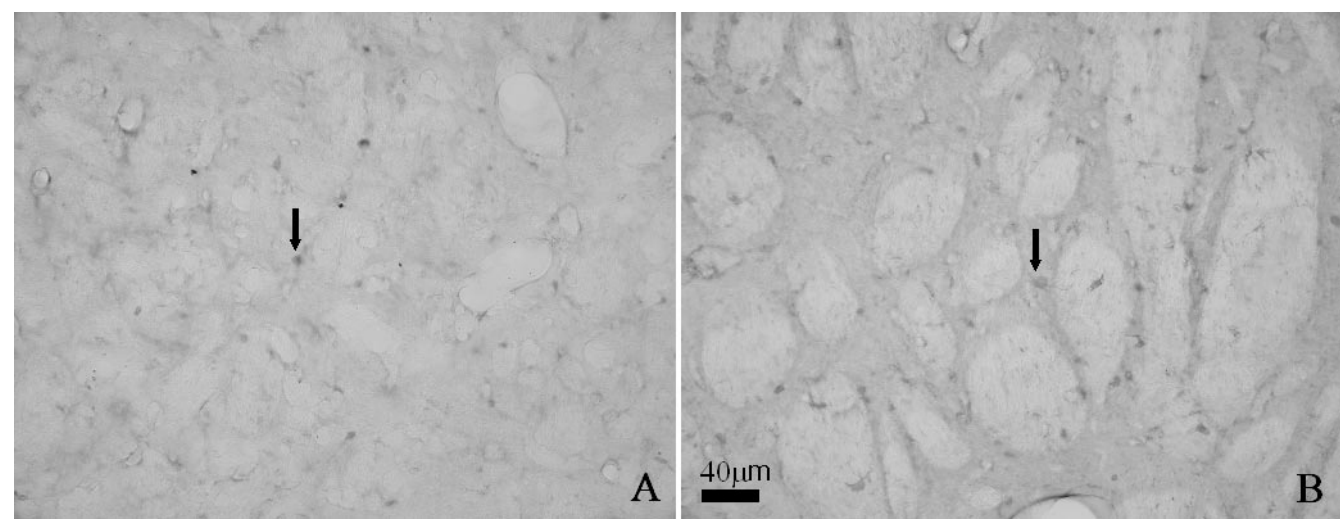

Fig. 2. Photomicrographs showing S100 $\beta$ immunoreactive (ir) structures in the striatum of the saline injected control (A) and Mn-intoxicated mice (B).

Increase of the $\mathrm{S} 100 \beta$ immunoreactivity and hypertrophic cells are observed in the Mn-intoxicated striatum (B) in comparison to control striatum (A). S100 $\beta$-ir cells are indicated by arrows.

arrays. The phosphorimaging signals of selected genes have been enlarged to provide a clearer depiction of the variance in gene expression observed in the array study. There were no significant changes in such as genes associated with carbohydrate metabolism, transcription factors, ion channel proteins, and immune system proteins in this array study.

Among these genes the S100 $\beta$ mRNA transcript was upregulated in the striatum and the SN by 4.93 folds and 3.26 folds, respectively, following Mn treatment.

Immunohistochemistry was used to determine whether striatal $\mathrm{S} 100 \beta$ protein level concurrently increased by $\mathrm{Mn}$ treatment. Activated astrocytes, immunoreactive for $\mathrm{S} 100 \beta$, increased in number and enlargement of their cell body size which are distinguishing features of astrocyte activation was compared with saline-treated control animals (Fig. 2). The optical density of $\mathrm{S} 100 \beta$ immunoreactivity in the striatum was significantly increased in the Mn-treated animals in compared to the saline-treated control animals $(1.28 \pm 0.22$ vs $0.79 \pm 0.15 ; \mathrm{P}<0.001)$. 


\section{Discussion}

This is the first cDNA array analysis of gene expression profiles in mice brain exposed to Mn to our best knowledge. We identified several genes in the mouse striatum and SN whose expressions are affected by Mn treatment through the use of the cDNA array. Most interesting observation is that the $\mathrm{S} 100 \beta$ mRNA transcript is up-regulated following treatment. This finding is significant because overexpression of $\mathrm{S} 100 \beta$ of the astrocyte-derived cytokine has been shown to be involved in neurodegenerative diseases ${ }^{8-10)}$. The immunohistochemical study revealed that striatal protein level of $\mathrm{S} 100 \beta$ also increased significantly after treatment, indicating that $\mathrm{Mn}$-induced $\mathrm{S} 100 \beta$ mRNA transcript upregulation was translated. This $\mathrm{Mn}$-induced increase in $\mathrm{S} 100 \beta$ overexpression is reminiscent of increases in $\mathrm{S} 100 \beta$ expression that accompany normal aging in both humans ${ }^{11}$ and experimental animals ${ }^{12)}$. In Alzheimer's disease, there are elevated tissue levels of both biologically active $\mathrm{S} 100 \beta$ protein and $\mathrm{S} 100 \beta \mathrm{mRNA}^{13)}$, and these increases correlated with overexpression of $\mathrm{S} 100 \beta$ by plaque-associated astrocytes $^{8,10,14)} . \mathrm{S} 100 \beta$ is a neurite growth-promoting cytokine $^{15)}$, and promotes astrocytic activation ${ }^{8)}$. The numbers of $\mathrm{S} 100 \beta$-overexpressing astrocytes correlated with the extent of dystrophic neurite formation in amyloid plaques of Alzheimer's disease ${ }^{10)}$. Mn-induced $\mathrm{S} 100 \beta$ overexpression, as shown here, supports the idea that activated astrocytes overexpressing $\mathrm{S} 100 \beta$ are important and necessary factors in the genesis of neuritic pathology in neurodegenerative disease.

Down-regulation of the heavy neurofilament subunit (NF-H) genes in striatum and light neurofilament subunit, NF-H genes in SN shown in the present study mean the neuronal degeneration in each region. Mn induced the specific degeneration of neuronal cytoskeletons, which is the common effect of neurodegenerative disease, including Parkinson's disease and Alzheimer's disease. Nacetylglucosaminyltransferase I gene which is related to transcript the protein modification enzyme increased in striatum and SN. This means increased transcription of Mn-related or binding proteins such as transferrin in the striatum and SN. Synaptonemal complex protein I is functionally unknown gene.

It is generally assumed that the substantia nigra pars compacta ( $\mathrm{SNpc}$ ) remains intact, and postsynaptic region is damaged in $\mathrm{Mn}$ intoxication ${ }^{16-18)}$. However, all our findings suggested that neuronal degenerations might occur in SN as well as striatum of mice exposed to $\mathrm{Mn}$. The present findings were compatible with some human pathologic findings ${ }^{19-23)}$, animal pathologic finding ${ }^{24)}$, and animal biochemical findings ${ }^{25,26}$. The present finding was also in accordance with our recent brain MRI studies on humans showing that $\mathrm{Mn}$ frequently deposits in midbrain as well as globus pallidus ${ }^{27,28)}$ and the hypertrophy of astrocytes by Mn intoxication in mouse brain finally ${ }^{7}$.

However, the present findings do not necessarily mean that $\mathrm{Mn}$ also damage dopaminergic pathway. The present findings have limitations of preliminary studies, and further studies need to be performed.

In summary, using cDNA array method, the present study showed several genes in the $\mathrm{SN}$ as well as striatum of mice exposed to Mn. Among them the $\mathrm{S} 100 \beta$ gene, was upregulated following Mn treatment. Furthermore, we showed that $\mathrm{Mn}$ exposure increased the expression of $\mathrm{S} 100 \beta$ at protein level in the astrocytes.

\section{Acknowledgments}

This work was supported by grant No. (R01-2000-00000162-0) from the Basic Research Program of the Korea Science \& Engineering Foundation.

\section{References}

1) Wedler FG, Denman RB (1984) Glutamine synthetase: the major Mn(II) enzyme in mammalian brain. Curr Top Cell Regul 24, 153-69.

2) Prohaska JR (1987) Functions of trace elements in brain metabolism. Physiol Rev 67, 858-901.

3) Donaldson J (1987) The physiopathologic significance of manganese in brain: its relation to schizophrenia and neurodegenerative disorders. Neurotoxicology $8,451-$ 62.

4) Ejima A, Imamura T, Nakamura S, Saito H, Matsumoto K, Momono S (1992) Manganese intoxication during total parenteral nutrition. Lancet 339, 426.

5) Nuwaysir EF, Bittner M, Trent J, Barrett JC, Afshari CA (1999) Microarray and toxicology: the advent of toxicogenomics. Mol Carcinog 24, 153-9.

6) Vrana KE, Freedman WM, Aschner M (2003) Use of microarray technologies in toxicology research. Neurotoxicology 24, 321-32.

7) Baek SY, Lee MJ, Jung HS, Kim HJ, Lee CR, Yoo, C, Lee JH, Lee H, Yoon CS, Kim YH, Park J, Kim JW, Jeon BS, Kim YH (2003) Effect of Manganese exposure on MPTP neurotoxicities. Neurotoxicology 24, 657-65.

8) Griffin WST, Stanley LC, Ling C, White CL III, Araoz C (1989) Brain interleukin-1 and S100 immunoreactivity 
elevated in Down syndrome and Alzheimer's disease. Proc Natl Acad Sci USA 86, 7611-5.

9) Griffin WST, Sheng JG, Mrak RE (1998) Senescenceaccelerated overexpression of S100 $\beta$ in brain of SAMP6 mice. Neurobiol Aging 19, 71-6.

10) Mrak RE, Sheng JG, Griffin WST (1996) Correlation of astrocytic $\mathrm{S} 100 \beta$ expression with dystrophic neurites in amyloid plaques of Alzheimer's disease. J Neuropathol Exp Neurol 55, 273-9.

11) Sheng J G, Mrak RE, Rovnaghi CR, Kozlowska E, Van Eldik LJ, Griffin WST (1996) Human brain S100 $\beta$ and S100 $\beta$ mRNA expression increases with age: pathogenic implications for Alzheimer's disease. Neurobiol Aging 17, 359-63.

12) Kato K, Suzuki F, Morishita R, Asano T, Sato $T$ (1990) Selective increase in $\mathrm{S} 100 \beta$ protein by aging in rat cerebral cortex. J Neurochem 54, 1269-74.

13) Marshak DR, Pesce SA, Stanley LC, Griffin WST (1991) Increased $S 100 \beta$ neurotrophic activity in Alzheimer disease temporal lobe. Neurobiol Aging 13, 1-7.

14) Sheng JG, Mrak RE, Griffin WST (1994) S100 $\beta$ protein expression in Alzheimer disease: potential role in the pathogenesis of neuritic plaques. J Neurosci Res 39, 398-404.

15) Kligman D, Marshak DR (1985) Purification and characterization of a neurite extension factor from bovine brain. Proc Natl Acad Sci USA 82, 7136-9.

16) Calne DB, Chu NS, Huang CC, Lu CS, Olanow W (1994) Manganism and idiopathic parkinsonism: similaritites and differences. Neurology 44, 1583-6.

17) Olanow CW, Good PF, Shinotoh H, Hewitt KA, Vingerhoets F, Snow BJ, Beal MF, Calne DB, Perl DP (1996) Manganese intoxication in the rhesus monkey: a clinical, imaging, pathologic, and biochemical study. Neurology 46, 492-8.

18) Shinotoh H, Snow BJ, Chu NS, Huang CC, Lu CS, Lee C, Takahashi H, Calne DB (1997) Presynaptic and postsynaptic striatal dopaminergic function in patients with manganese intoxication: a positron emission tomography study. Neurology 48, 1053-5.

19) Ashizawa $R$ (1927) Über einen Sektionsfall von chronischer Manganvergiftung. Jpn J Med Sci Trans, Sect VIII, Int Med Pediat Psychiat 1, 173-91.

20) Scholten JM (1953) On manganese encephalopathy. Folia Psychiatr Neurol 56, 878-84.

21) Cotzias GC (1969) Metabolic modification of some neurologic disorders. JAMA 210, 1255-62.

22) Mena I, Court J, Fuenzalida S, Papavasiliou PS, Cotzias GC (1970) Modification of chronic manganese poisionig: treatment with $\mathrm{L}-$ dopa or 5-OH tryptophane. N Engl J Med 282, 5-10.

23) Bernheimer $\mathrm{H}$, Birkmayer $\mathrm{W}$, Hornykiewicz $\mathrm{O}$, Jellinger K, Seitelberger F (1973) Brain dopamine and the syndromes of Parkinson and Huntington. Clinical, morphological and neurochemical correlations. J Neurol Sci 20, 415-55.

24) Gupta SK, Murthy RC, Chandra SV (1980) Neuromelanin in manganese-exposed primates. Toxicol Lett 6, 17-20.

25) Gianutsos G, Murray MT (1982) Alterations in brain dopamine and GABA following inorganic or organic manganese administration. Neurotoxicology 3, 75-82.

26) Komura J, Sakamoto M (1992) Effects of manganese forms on biogenic amines in the brain and behavioral alterations in the mouse: Long-term oral administration of several manganese compounds. Environ Res 57, 34 44.

27) Kim Y, Kim KS, Yang JS, Park IJ, Kim E, Jin Y, Kwon KR, Chang KH, Kim JW, Lin HS, Cheon HK, Shin YC, Park J, Moon Y (1999) Increase in signal intensities on $\mathrm{T} 1$-weighted magnetic resonance images in asymptomatic manganese-exposed workers. Neurotoxicology 20, 901-8.

28) Park NH, Park JK, Choi Y, Yoo C-I, Lee CR, Lee H, Kim HK, Kim S-R, Jung T-H, Park J, Yoon CS, Kim Y (2003) Whole blood manganese correlates with high signal intensities on T1-weighted MRI in patients with liver cirrhosis. Neurotoxicology 24, 909-15. 